\title{
Nosocomial Infections Among COVID-19 Patients: an Analysis of Prospective Intensive Care Unit Surveillance Data
}

Clara Chong Hui Ong

NCID: National Centre for Infectious Diseases

Sharifah Farhanah

NCID: National Centre for Infectious Diseases

Kyaw Zaw Linn

NCID: National Centre for Infectious Diseases

Ying Wei Tang

NCID: National Centre for Infectious Diseases

Chu Ying Poon

NCID: National Centre for Infectious Diseases

Allie Yin Lim

NCID: National Centre for Infectious Diseases

Hui Ru Tan

NCID: National Centre for Infectious Diseases

Nur Hafizah Binte Hamed

NCID: National Centre for Infectious Diseases

Xiaowei Huan

NCID: National Centre for Infectious Diseases

Ser Hon Puah

Tan Tock Seng Hospital

Benjamin Choon Heng Ho

Tan Tock Seng Hospital

Margaret Mei Ling Soon

NCID: National Centre for Infectious Diseases

Brenda Sze Pang Ang

NCID: National Centre for Infectious Diseases

\section{Shawn Vasoo}

NCID: National Centre for Infectious Diseases

\section{Monica Chan}

Tan Tock Seng Hospital

\section{Yee Sin Leo}

https://orcid.org/0000-0002-2890-9326 
NCID: National Centre for Infectious Diseases

\section{Oon Tek Ng}

Tan Tock Seng Hospital

Kalisvar Marimuthu ( $\nabla$ kalisvar_marimuthu@ttsh.com.sg )

National Centre for Infectious Diseases https://orcid.org/0000-0002-0395-5633

\section{Short report}

Keywords: Healthcare-associated Infections (HAI), Device-associated nosocomial Infections, COVID-19 outbreak, SARS-CoV-2, Intensive Care Units (ICU), catheter-associated urinary tract infection (CAUTI)

Posted Date: June 7th, 2021

DOl: https://doi.org/10.21203/rs.3.rs-571224/v1

License: (1) (i) This work is licensed under a Creative Commons Attribution 4.0 International License. Read Full License

Version of Record: A version of this preprint was published at Antimicrobial Resistance and Infection Control on August 12th, 2021. See the published version at https://doi.org/10.1186/s13756-021-00988-7. 


\section{Abstract}

Surveillance of nosocomial infections, like catheter-associated urinary tract infection (CAUTI), central lineassociated bloodstream infection (CLABSI), possible ventilator-associated pneumonia (PVAP) and secondary bloodstream infections were observed to study the impact of COVID-19 outbreak in ICUs from Tan Tock Seng Hospital and National Centre for Infectious Diseases, Singapore between February and June 2020. Higher nosocomial infection rates were observed in COVID-19 patients, although it was not statistically significant. Moreover, COVID-19 patients seem to be more predisposed to CAUTI despite a higher proportion of non-COVID-19 patients having urinary catheters. Thus, continued vigilance to ensure adherence to IPC measures is needed.

\section{Summary}

Surveillance of nosocomial infections, like catheter-associated urinary tract infection (CAUTI), central lineassociated bloodstream infection (CLABSI), possible ventilator-associated pneumonia (PVAP) and secondary bloodstream infections were observed to study the impact of COVID-19 outbreak in ICUs from Tan Tock Seng Hospital and National Centre for Infectious Diseases, Singapore between February and June 2020. Higher nosocomial infection rates were observed in COVID-19 patients, although it was not statistically significant. Moreover, COVID-19 patients seem to be more predisposed to CAUTI despite a higher proportion of non-COVID-19 patients having urinary catheters. Thus, continued vigilance to ensure adherence to IPC measures is needed.

\section{Introduction}

With the COVID-19 pandemic continuing globally, the prevention of nosocomial infections is more crucial than ever as secondary nosocomial infections may increase the morbidity and mortality of COVID-19 patients and have been recommended as part of the clinical outcomes to measure for COVID-19.(1) The effectiveness of existing infection prevention and control (IPC) strategies in preventing nosocomial infections among patients, in the middle of a pandemic, is unknown. While low levels of T cells were reported among COVID-19 patients,(2) suggesting that there is some suppression of the immune system, (3) the impact of secondary infections is unknown. During the pandemic, in most healthcare facilities, IPC resources are preferentially diverted for outbreak response which may increase the incidence of nosocomial infections among all hospitalized patients.(4)

Hence, there is a need to obtain robust data based on established surveillance methods to understand the impact of COVID-19 outbreak on nosocomial infections. As part of the outbreak response, we conducted prospective surveillance for device-associated infections (DAI) and secondary nosocomial bacteraemia in intensive care units (ICU) using National Healthcare Safety Network (NHSN) criteria. We report the findings from the surveillance in this report.

\section{Methods}




\section{Study design and setting}

We conducted prospective surveillance at the National Centre for Infectious Diseases (NCID), a 330bedded purpose-built outbreak response facility with $38 \mathrm{ICU}$ beds and Tan Tock Seng Hospital (TTSH), a 1700-bedded acute hospital with 72 ICU beds. Outbreak ICUs and medical ICUs wards $(n=4)$ were included in this surveillance. The surveillance was conducted from 1st February to 30th June 2020 during COVID-19 epidemic in Singapore.

\section{Patient Selection and follow up}

All patients admitted to the four ICUs were included in the surveillance. Patients who were suspected of or confirmed to have COVID-19 were managed in the outbreak ICUs. Once patients were cleared of or recovered from COVID-19(5), they were transferred to other ICUs or general wards as clinically indicated.

Patients were reviewed daily by five trained surveillance coordinators starting from the day of admission to ICU until 2 days after they were transferred to the general ward or discharged. For patients with multiple ICU admissions during a single hospitalization episode, only the first episode was included in this analysis. The outcomes of interest were nosocomial infections, including catheter-associated urinary tract infection (CAUTI), central line-associated bloodstream infection (CLABSI), possible ventilatorassociated pneumonia (PVAP) and secondary bloodstream infections.

\section{Data collection and Definitions}

Data were extracted from electronic medical records using Research Electronic Data Capture (REDCap) software hosted at National Healthcare Group, Singapore.(6) The Domain Specific Review Board (DSRB) of National Healthcare Group (NHG) provided ethical approval for the study (DSRB: 2020/01242).

At baseline, we recorded the age, gender, comorbidities (based on Charlson's comorbidity index), immunosuppression status (i.e. recent chemotherapy in last 6 month, TNF-alpha blocker in last month, or taking prednisolone $10 \mathrm{mg} /$ day or equivalent steroid on admission), and date of transfer to ICU. Patients were reviewed daily to collect data for presence of invasive devices (i.e. indwelling urinary catheter, central line or endotracheal intubation), microbiological cultures, histopathological tests, radiological investigations and symptoms of nosocomial infections. Data collection form is provided in the supplementary material. The definitions of device-associated infections, including CAUTI, CLABSI, PVAP and BSI, were standardized according to the criteria provided by the CDC-NHSN.(7)

\section{Statistical methods}

We compared the baseline characteristics of COVID-19 and non-COVID-19 patients with Chi-squared tests for categorical variables, and Wilcoxon rank-sum test for continuous variables. We calculated the incidence rates (Number of nosocomial infections per 1000 ICU-days or per 1000 device days) for secondary bacteraemia, CAUTI, CLABSI, and PVAP, and all nosocomial infections (combination of all nosocomial infections under surveillance). We described the monthly trend of nosocomial infections comparing COVID-19 and non-COVID-19 patients in ICUs. Hazard ratios comparing COVID-19 and non- 
COVID-19 patients were calculated using the Mantel-Haenszel method. A poisson regression model was used to adjust the hazard ratio for the overall nosocomial infections among COVID-19 patients for age, gender, comorbidities, length of stay in ICU, and the presence of invasive devices. The number of events were too small to calculate the adjusted hazard ratio for individual nosocomial infection. All statistical analysis was performed using STATA version 15.0 statistical software.

\section{Results}

A total of 650 patients underwent surveillance for nosocomial infections. Ninety-two patients with incomplete data were excluded (Supplementary Fig. 1). Of the 558 patients included in the final analysis, 71 were COVID-19 patients and 487 non-COVID-19 patients. Of these, $64.2 \%$ were male patients, and the median age of the cohort was 65 years [Interquartile range (IQR): 53-74]. COVID-19 patients were younger, had fewer comorbidities, and stayed longer in ICU (Table 1). COVID-19 patients had indwelling urinary catheters, invasive mechanical ventilation, and central venous lines for a longer duration compared to non-COVID-19 patients (Table 2). 
Table 1

Distribution of baseline characteristics among COVID-19 patients and non-COVID-19 patients in the ICU

\begin{tabular}{|c|c|c|c|c|}
\hline Baseline characteristics & $\begin{array}{l}\text { CoVID-19 } \\
\text { patients }(n=71)\end{array}$ & $\begin{array}{l}\text { Non-COVID-19 } \\
\text { patients }(n=487)\end{array}$ & $\begin{array}{l}\text { All patients } \\
(\mathrm{n}=558)\end{array}$ & $\begin{array}{l}\text { Chi- } \\
\text { squared } \\
\text { test }\end{array}$ \\
\hline Age, Median (IQR) ${ }^{\mathrm{a}}$ & $52(39-66)$ & $66(55-75)$ & $65(53-74)$ & $<0.001$ \\
\hline Male & $59(83.10)$ & $299(61.40)$ & $358(64.16)$ & $<0.001$ \\
\hline $\begin{array}{l}\text { Length of stay in ICU, } \\
\text { Median days (IQR) }\end{array}$ & $6(2-9)$ & $2(1-4)$ & $2(2-4)$ & $<0.001$ \\
\hline \multicolumn{5}{|l|}{ Underlying diseases } \\
\hline Overall comorbidities & $25(35.21)$ & $342(70.23)$ & $367(65.77)$ & $<0.001$ \\
\hline $\begin{array}{l}\text { Chronic pulmonary } \\
\text { diseases }\end{array}$ & $2(2.82)$ & $60(12.32)$ & $62(11.11)$ & - \\
\hline Cardiovascular diseases & $4(5.63)$ & $100(20.53)$ & $104(18.64)$ & - \\
\hline Connective tissue disease & $0(0.00)$ & $11(2.26)$ & $11(1.97)$ & - \\
\hline Peptic ulcer disease & $0(0.00)$ & $13(2.67)$ & $13(2.33)$ & - \\
\hline $\begin{array}{l}\text { Chronic neurological } \\
\text { diseases }\end{array}$ & $2(2.82)$ & $79(16.22)$ & $81(14.52)$ & - \\
\hline Chronic kidney disease & $5(7.04)$ & $125(25.67)$ & $130(23.30)$ & - \\
\hline Diabetes Mellitus & $19(26.76)$ & $197(40.45)$ & $216(38.71)$ & - \\
\hline Malignant diseases & $1(1.41)$ & $82(16.84)$ & $83(14.87)$ & - \\
\hline Chronic liver diseases & $1(1.41)$ & $24(4.93)$ & $25(4.48)$ & - \\
\hline Immunosuppression & $2(2.82)$ & $30(6.16)$ & $32(5.73)$ & - \\
\hline
\end{tabular}


Table 2

Incidence rate, hazard ratios, $95 \% \mathrm{Cl}$ and significance tests for various types of nosocomial infections by COVID-19 status

\begin{tabular}{|c|c|c|c|}
\hline & $\begin{array}{l}\text { COVID-19 patients } \\
(n=71)\end{array}$ & $\begin{array}{l}\text { Non-COVID-19 patients } \\
(n=487)\end{array}$ & $\begin{array}{l}\mathrm{P} \text { - } \\
\text { value }\end{array}$ \\
\hline \multicolumn{4}{|l|}{ Nosocomial infection } \\
\hline Total ICU-days & 727 & 1847 & - \\
\hline Episodes of nosocomial infection & $10^{\mathrm{a}}$ & $13^{b}$ & - \\
\hline $\begin{array}{l}\text { Incidence of nosocomial infection per } 1000 \\
\text { ICU-days }(95 \% \mathrm{Cl})\end{array}$ & $13.76(7.40-25.56)$ & $7.04(4.09-12.12)$ & - \\
\hline Hazard Ratio & $1.95(0.86-4.46)$ & 1 & 0.105 \\
\hline Adjusted Hazard Ratio ${ }^{c}$ & $1.59(0.60-4.21)$ & - & 0.353 \\
\hline \multicolumn{4}{|l|}{ CAUTI } \\
\hline Indwelling urinary catheter & $42(59.15)$ & $354(72.69)$ & 0.019 \\
\hline $\begin{array}{l}\text { Duration of indwelling catheter, Median } \\
\text { days (IQR) }{ }^{d}\end{array}$ & $6.5(4-14)$ & $2(2-4)$ & $<.001$ \\
\hline Total Catheter-days & 555 & 1443 & - \\
\hline Episodes of CAUTI & 4 & 1 & - \\
\hline $\begin{array}{l}\text { Incidence of CAUTI per } 1000 \text { catheter-days } \\
(95 \% \mathrm{Cl})\end{array}$ & $7.21(2.70-19.20)$ & $0.69(0.10-4.92)$ & - \\
\hline Hazard Ratio $(95 \% \mathrm{Cl})$ & $\begin{array}{l}10.40(1.16- \\
93.05)\end{array}$ & 1 & 0.009 \\
\hline \multicolumn{4}{|l|}{ CLABSI } \\
\hline Number of patients on central line & $27(38.03)$ & $191(39.22)$ & 0.848 \\
\hline Duration of central line, Median Days (IQR) ${ }^{\mathrm{d}}$ & $9(6-23)$ & $3(2-7)$ & $<.001$ \\
\hline Total Central line-days & 418 & 1050 & - \\
\hline Episodes of CLABSI & 0 & 2 & - \\
\hline $\begin{array}{l}\text { Incidence of CLABSI per } 1000 \text { central line- } \\
\text { days }(95 \% \mathrm{Cl})\end{array}$ & 0 & $1.90(0.48-7.62)$ & - \\
\hline Hazard Ratio $(95 \% \mathrm{Cl})$ & - & - & - \\
\hline \multicolumn{4}{|l|}{ PVAP } \\
\hline Invasive mechanical ventilation & $27(38.03)$ & $222(45.59)$ & 0.231 \\
\hline
\end{tabular}




\begin{tabular}{|c|c|c|c|}
\hline & $\begin{array}{l}\text { COVID-19 patients } \\
(\mathrm{n}=71)\end{array}$ & $\begin{array}{l}\text { Non-COVID-19 patients } \\
(n=487)\end{array}$ & $\begin{array}{l}\mathrm{P}- \\
\text { value }\end{array}$ \\
\hline $\begin{array}{l}\text { Duration of mechanical ventilation, Median } \\
\text { Days }(\text { IQR })^{d}\end{array}$ & $8(5-26)$ & $3(1-5)$ & $\dot{0} 001$ \\
\hline Total Ventilator-days & 471 & 1150 & - \\
\hline Episodes of PVAP & 1 & 2 & - \\
\hline $\begin{array}{l}\text { Incidence of PVAP per } 1000 \text { ventilator-days } \\
(95 \% \mathrm{Cl})\end{array}$ & $2.12(0.30-15.07)$ & $1.74(0.43-6.95)$ & - \\
\hline Hazard Ratio $(95 \% \mathrm{Cl})$ & $1.22(0.11-13.46)$ & 1 & 0.87 \\
\hline \multicolumn{4}{|l|}{ Secondary Bloodstream infection (BSI) } \\
\hline ICU-days & 727 & 1847 & - \\
\hline Episodes of BSI & 5 & 8 & - \\
\hline Incidence of BSI per 1000 ICU-days (95\%CI) & $6.88(2.86-16.52)$ & $4.33(2.17-8.66)$ & - \\
\hline Hazard Ratio $(95 \% \mathrm{Cl})$ & $1.59(0.52-4.85)$ & 1 & 0.413 \\
\hline \multicolumn{4}{|c|}{$\begin{array}{l}\text { a - From the } 10 \text { nosocomial infections, a total of } 11 \text { organisms were detected. There were } 2(18.18 \%) \\
\text { Klebsiella pneumoniae, } 2(18.18 \%) \text { Escherichia coli, } 1(9.09 \%) \text { Enterobacter cloacae, } 2(18.18 \%) \\
\text { Pseudomonas aeruginosa, } 1(9.09 \%) \text { Pseudomonas species, } 1(9.09 \%) \text { Enterococcus faecium, } 1 \\
\text { (9.09\%) coagulase-negative Staphylococcus,and } 1 \text { ( } 9.09 \%) \text { Candida species detected. All } \\
\text { enterobacteriaceae and non-fermenters organisms were sensitive to carbapenem. }\end{array}$} \\
\hline \multicolumn{4}{|c|}{$\begin{array}{l}\text { b- From the } 13 \text { nosocomial infections, a total of } 17 \text { organisms were detected. There were } 3(17.65 \%) \\
\text { Klebsiella pneumoniae, } 1(5.88 \%) \text { Escherichia coli, } 1(5.88 \%) \text { Enterobacter aerogenes, } 1(5.88 \%) \\
\text { Pseudomonas aeruginosa, } 1(5.88 \%) \text { Enterococcus faecium, } 4(23.53 \%) \text { Staphylococcus auerus, and } \\
6(35.29 \%) \text { Candida species detected. All enterobacteriaceae and non-fermenters organisms were } \\
\text { sensitive to carbapenem. Of the } 4 \text { Staphylococcus Auerus, } 1 \text { was methicillin resistant. }\end{array}$} \\
\hline \multicolumn{4}{|c|}{$\begin{array}{l}\text { c- Adjusted for age, gender, comorbidity as a whole, length of stay in ICU, presence of IDC, presence of } \\
\text { invasive ventilation and presence of central line }\end{array}$} \\
\hline
\end{tabular}

\section{Incidence of nosocomial infections}

During the study period, $14.8 \%$ (10/71) developed nosocomial infections in COVID-19 patients, and a total of 11 organisms were detected (Table 2). Two (18.18\%) Klebsiella Pneumoniae, two (18.18\%) Escherichia coli, one (9.09\%) Enterobacter cloacae, two (18.18\%) Pseudomonas aeruginosa, one $(9.09 \%)$ Pseudomonas species, one (9.09\%) Enterococcus faecium, one (9.09\%) coagulase-negative Staphylococcus, and one (9.09\%) Candida species were detected. All enterobacteriaceae and nonfermenters organisms were carbapenem-sensitive. Moreover, $2.7 \%$ (13/487) of non-COVID-19 patients 
developed nosocomial infections and 17 organisms were detected. There were three $(17.65 \%) \mathrm{K}$. Pneumoniae, one (5.88\%) E. coli, one (5.88\%) E. aerogenes, one (5.88\%) P. aeruginosa, one (5.88\%) E. faecium, four (23.53\%) S. auerus, and six (35.29\%) Candida species. Only one out of four was MethicillinResistant $\mathrm{S}$. auerus while all enterobacteriaceae and non-fermenters organisms were carbapenemsensitive (Table 2).

The incidence rates of all nosocomial infections among COVID-19 and non-COVID-19 patients were 13.76 per 1000 ICU-days [95\% confidence interval $(\mathrm{Cl}), 7.40-25.56$ ] and 7.04 per 1000 ICU-days $(95 \% \mathrm{Cl}, 4.09$ 12.12) $(P=0.11)$ respectively (Table 2$)$. After adjusting for age, gender, comorbidities, length of stay in $\mathrm{ICU}$, and the presence of devices, there was no significant difference in the hazard ratio for nosocomial infections among COVID-19 patients [adjusted hazard ratio (HR), 1.59; $95 \% \mathrm{Cl}, 0.60-4.21 ; \mathrm{P}=0.35$ ]. There was a higher incidence of CAUTI among COVID-19 patients and a significant difference in the unadjusted hazard ratio for CAUTI among COVID-19 patients (unadjusted HR, 10.40; 95\% Cl, 1.16-93.50; P=0.01), as the number of events were too small to calculate the adjusted hazard ratio for individual nosocomial infection. However, no difference was observed for CLABSI, PVAP, and secondary bacteraemia.

The monthly rate of nosocomial infection among COVID-19 patients peaked in May 2020 at 22.99 per 1000 ICU-days in COVID-19 patients (Supplementary Fig. 2). The nosocomial infection rate for nonCOVID-19 patients remained relatively stable during the study period. During the study period, the risk of nosocomial infections remained higher among COVID-19 patients compared to non-COVID-19 patients (Supplementary Fig. 3).

\section{Discussion}

In our study, the nosocomial infection rate in the ICU was noted to be higher among COVID-19 patients compared to non-COVID-19 patients; however, it was not statistically significant. COVID-19 patients seem to be more predisposed to catheter-associated urinary tract infection (CAUTI) despite a higher proportion of non-COVID-19 patients having urinary catheters.

Additionally, on top of having invasive devices, critically ill COVID-19 patients may have increased susceptibility to nosocomial infections due to lymphopenia and reduced immune functions.(3) Studies have observed lymphopenia present in COVID-19 patients, which was also reflected in our preliminary observations in our first few COVID-19 cases in Singapore. $(2,8)$ Additionally, steroids was not part of standard treatment for acute respiratory distress syndrome in our COVID-19 patients. Furthermore, the COVID-19 virus evades the immune system through the inhibition of interferon type I recognition and signalling, prevents recognition of antigen-presenting plasma and myeloid dendritic cells,(3) and undermines lymphocytic activation,(9) possibly increasing the hazard for COVID-19 patients to acquire nosocomial infections. However, further studies are warranted to determine if lymphopenia and paresis of other components of the immune response plays a part in nosocomial infections in COVID-19.

Furthermore, the relatively stable nosocomial infection rate in non-COVID-19 patients during the study could also be attributed to heightened infection prevention and control practices during the COVID-19 
outbreak. Enhanced precautions, such as improved hand hygiene practices decreases the transmission of nosocomial infections between patients in the ICU. However, changes in care practices such as minimizing contact with suspected or confirmed COVID-19 patients and rostering of available manpower could possibly affect nosocomial infection rates, such as CAUTI in COVID-19 patients as opposed to nonCOVID-19 patients. All ICUs in TTSH and NCID are also protocolled to nurse patients in the semirecumbent position unless contraindicated, which reduces the risks of PVAP infection in both patients' group. Thus, longer length of stay, use of invasive devices, and reduced immune functions could be potential reasons which resulted in a higher nosocomial infection rate in COVID-19 patients compared to non-COVID-19 patients. $(4,10)$

Our study has several limitations. First, the small number of nosocomial infections makes it difficult to analyse the risk factors for nosocomial infections. Second, we did not audit the adherence to process measures that were in place to prevent nosocomial infections. Hence, we were unable to identify the reasons for CAUTI being the main device-associated infection in COVID-19 patients. However, as seen in other studies,(10) it is likely due to changes in care practices in COVID-19 ICU wards which could have resulted in suboptimal compliance to IPC measures and thus, longer duration of urinary catheter use.

In conclusion, although the incidence of nosocomial infection was not significantly affected by COVID-19 in our centre, continued vigilance to ensure adherence to IPC measures is needed.

\section{Declarations}

\section{Ethics approval and Conflict of interests}

The Domain Specific Review Board (DSRB) of National Healthcare Group (NHG) provided ethical approval for the study (DSRB: 2020/01242). We confirm that this work is original and has not been published, nor is under consideration for publication elsewhere, that the submitted article has been approved by all authors. All authors report no conflict of interest pertinent to this manuscript.

\section{Financial support}

This work was supported by the National Medical Research Council Clinician Scientist Award at Singapore Ministry of Health ( $\mathrm{MOH}-000276)$ to $\mathrm{Dr} \mathrm{Ng}$ Oon Tek and German Federal Ministry of Health (BMG) COVID-19 Research and development funding to WHO.

\section{Author's Contribution}

MMLS, BSPA, KM and OTN conceived the study while KM planned and supervised the study. YWT, CYP, AYL, HRT, NHBH extracted the data from electronic medical records; $\mathrm{XH}, \mathrm{SHP}$, and $\mathrm{BCHH}$ verified the data, and KZL performed data quality check and statistical analysis. $\mathrm{CCHO}$ and SF interpreted the data and drafted the manuscript with input from all the other authors, MMLS, BSPA, SV, MC, and YSL. All the authors provided critical feedback on the analysis and manuscript done and that the submitted article has been approved by all authors 
Acknowledgements

We would like to thank National Centre of Infectious Disease's Nursing team and Infection Prevention and Control team for their continuous effort and commitment during the COVID-19 outbreak.

\section{References}

1. Marshall JC, Murthy S, Diaz J, Adhikari NK, Angus DC, Arabi YM, et al. A minimal common outcome measure set for COVID-19 clinical research. The Lancet Infectious Diseases. 2020;20(8):e192-e7.

2. Xu B, Fan CY, Wang AL, Zou YL, Yu YH, He C, et al. Suppressed T cell-mediated immunity in patients with COVID-19: A clinical retrospective study in Wuhan, China. J Infect. 2020;81(1):e51-e60.

3. Arunachalam PS, Wimmers F, Mok CKP, Perera RAPM, Scott M, Hagan T, et al. Systems biological assessment of immunity to mild versus severe COVID-19 infection in humans. Science. 2020;369(6508):1210-20.

4. Stevens MP, Doll M, Pryor R, Godbout E, Cooper K, Bearman G. Impact of COVID-19 on traditional healthcare-associated infection prevention efforts. Infection Control and Hospital Epidemiology. 2020:1-2.

5. Tay J-Y, Lim PL, Marimuthu K, Sadarangani SP, Ling LM, Ang BSP, et al. De-isolating Coronavirus Disease 2019 Suspected Cases: A Continuing Challenge. Clinical Infectious Diseases. 2020;71(15):883-4.

6. Harris PA, Taylor R, Minor BL, Elliott V, Fernandez M, O'Neal L, et al. The REDCap consortium: Building an international community of software platform partners. Journal of Biomedical Informatics. 2019;95:103208.

7. CDC. National Healthcare Safety Network (NHSN) Patient Safety Component Manual2020 2020-0825. Available from: https://www.cdc.gov/nhsn/.

8. Young BE, Ong SWX, Kalimuddin S, Low JG, Tan SY, Loh J, et al. Epidemiologic Features and Clinical Course of Patients Infected With SARS-CoV-2 in Singapore. JAMA. 2020;323(15):1488-94.

9. Chang F-Y, Chen H-C, Chen P-J, Ho M-S, Hsieh S-L, Lin J-C, et al. Immunologic aspects of characteristics, diagnosis, and treatment of coronavirus disease 2019 (COVID-19). Journal of Biomedical Science. 2020;27(1):72.

10. McMullen KM, Smith BA, Rebmann T. Impact of SARS-CoV-2 on hospital acquired infection rates in the United States: Predictions and early results. American Journal of Infection Control. 2020.

\section{Supplementary Files}

This is a list of supplementary files associated with this preprint. Click to download.

- SupplementaryMaterialsNosocomiallnfections.docx 